NEWS AND COMMENTARY

Parkinson's Disease

\section{. \\ The LRRK2-G2019S mutation: opening a novel era in Parkinson's disease genetics}

Vincenzo Bonifati

European Journal of Human Genetics (2006) 14, 1061-1062.

doi:10.1038/sj.ejhg.5201695; published online 12 July 2006

$\mathrm{T}$

he role of genetic factors in the etiology of Parkinson's disease (PD) has long been considered negligible, but a series of recent discoveries are dramatically changing this view. Two studies recently published in The New England Journal of Medicine report an astonishing high prevalence of a single mutation in leucine-rich repeat kinase 2 (LRRK2), G2019S, in North African Arabs and Ashkenazi Jews with PD. ${ }^{1,2}$

Mutations in the LRRK2 gene were first identified in 2004 in families with autosomal-dominant $\mathrm{PD}^{3,4}$ soon thereafter, the G2019S mutation (c.G6055A) was identified by several groups as a common cause of this disease, being found not only in $\sim 5-6 \%$ of familial PD but also in $\sim 1-$ $2 \%$ of sporadic PD in several European and US populations. ${ }^{5-9}$

In one of the novel studies, ${ }^{2} 22$ out of 120 Ashkenazi Jewish patients with PD (18.3\%, 95\% confidence intervals (CI) $11.9-26.4)$ and four of 317 controls $(1.3 \%$, CI $0.34-3.2)$ carried the G2019S mutation. The risk of developing PD increased 17.6-fold (CI 5.9-52.2) in those who carry the mutation. G2019S was significantly more frequent among familial $(29.7 \%)$ than sporadic PD probands (13.3\%) and a lifetime penetrance of $31.8 \%$ was estimated for the mutation. The other study found G2019S in 30 out of 76 Arab PD probands (39\%) and two of 151 controls (3\%) all from North Africa; ${ }^{1}$ moreover, 37 and $41 \%$ were found to carry the mutation among familial and sporadic $\mathrm{PD}$, respectively. In this case, the odds ratio for developing PD among all G2019S carriers reached an even greater figure of 48.6 (CI 11.2-211.0). The low penetrance and censor effects likely explain the high G2019S prevalence in sporadic PD and its rare occurrence in controls (especially the younger individuals).

The relevance of these values is better appreciated if one considers that PD is the most frequent degenerative movement disorder, with a prevalence approaching $2 \%$ in Western countries, in people aged more than 65 years. Being an age-related disease, the number of patients will undoubtedly increase in the future, and PD will become an even bigger public health problem. Although therapies are effective in symptomatic control, none is currently able to stop or slow down the disease progression.

In most patients PD is sporadic, but in $10-15 \%$ of cases it runs in families, and more rarely, it segregates as a Mendelian trait with either autosomal-dominant or recessive inheritance. Mutations in the $\alpha$ synuclein gene cause autosomal-dominant forms, whereas mutations in the parkin, DJ-1 and PINK1 gene cause autosomalrecessive forms. Parkin mutations are frequent in cases of early onset, but mutations in all the above-mentioned genes are very rare in the patients with the classic, late-onset PD form. ${ }^{10}$

$L R R K 2$ is the first gene that is frequently mutated in autosomal-dominant PD of late onset. ${ }^{11}$ In addition, the discovery of G2019S established for the first time the proof-of-principle for a genetic determinant frequently involved in sporadic PD. ${ }^{7,8,12}$ The evidence that G2019S is pathogenic is overwhelming. This mutation is very frequent in PD and extremely rare in controls, ${ }^{5-8,12}$ and it cosegregates with PD in large families. ${ }^{6,8,13}$ The G2019 residue is extremely conserved in LRRK2 homologs and the mutation increases the kinase activity of the protein. ${ }^{14}$

However, the prevalence of G2019S is population specific: very rare in Asia, ${ }^{15}$ low in Northern Europe, ${ }^{8}$ and high in Italy, ${ }^{12}$ Spain ${ }^{16}$ and Portugal. ${ }^{17}$ Haplotype analyses revealed that all carriers of this mutation inherited the same ancestral chromosome. $^{8,12,18}$

After these two latest studies, it is clear that the prevalence of G2019S is highest among Arabs patients from North Africa and among Ashkenazi Jewish, also suggesting likely regions of origin of the mutation.

If the reported data will be confirmed, this mutation represents the most important known determinant of PD in several populations. However, the CI for the prevalence estimates are still wide. It is important to study a larger series of cases and ethnically matched controls, to refine and extend these figures. It is also crucial to assess the penetrance of the mutation more accurately. Earlier figures obtained in selected samples of dominant families were likely overestimated, ${ }^{8}$ and values should be calculated in unselected, consecutive series, ideally from populationbased studies. Screening in other populations can reveal further clues about the origin of this founder mutation. The astonishing figures obtained in Arabs and Ashkenazi Jews raise the question whether a positive selection is also shaping the population prevalence of G2019S in North Africa and the Middle East.

The discovery of G2019S has set the stage for PD entering fully the field of medical genetics. However, whether and when G2019S testing might be used for genetic counselling should await a much deeper understanding of the mechanisms of the disease caused by this and other LRRK2 mutations, and of the factors governing their penetrance.

Likely, other secrets concerning how G2019S causes PD remain to uncover. A few carriers of the G2019S mutation also carry parkin gene mutations. ${ }^{1,13}$ Digenic or polygenic inheritance could explain the lack of a Mendelian pattern of inheritance in most PD families. We do not 
currently understand the mechanisms underlying the large variability in onset age and other clinical features, observed even among the members of the same G2019S family; other factors must modify the expression and progression of the disease. In this sense, the G2019S mutation recapitulates the complexity of PD etiology in general. But now that so many PD cases can be identified with a common genetic determinant, it will be easier to design screens for modifiers.

Unravelling the pathobiology of the LRRK2-related PD might have far-reaching consequences for all patients with PD. Initial findings suggest that PD-causing mutations increase the kinase activity of the LRRK2 protein. ${ }^{14,19}$ Protein kinases are good targets for small-molecule drugs, and modulating the LRRK2 activity could become an innovative therapeutic strategy for all patients with PD.

But perhaps the most important implication of the G2019S mutation, which is now strengthened by the studies in Arabs and Ashkenazi Jews, is a conceptual one: to have brought the etiology of familial and sporadic PD closer than they have ever been

Dr V Bonifati is at the Department of Clinical Genetics, Erasmus MC Rotterdam, PO Box 1738, 3000 DR Rotterdam, The Netherlands.

Tel: 003110 4087382; Fax: 003110 4089461;

E-mail:v.bonifati@erasmusmc.nl

\section{References}

1 Lesage S, Durr A, Tazir M et al: LRRK2 G2019S as a cause of Parkinson's disease in North African Arabs. N Engl J Med 2006; 354: 422-423.

2 Ozelius LJ, Senthil G, Saunders-Pullman R et al: LRRK2 G2019S as a cause of Parkinson's disease in Ashkenazi Jews. $N$ Engl $J$ Med 2006; 354: 424-425.

3 Paisan-Ruiz C, Jain S, Evans EW et al: Cloning of the gene containing mutations that cause PARK8-linked Parkinson's disease. Neuron 2004; 44: 595-600.

4 Zimprich A, Biskup S, Leitner P et al: Mutations in LRRK2 cause autosomaldominant parkinsonism with pleomorphic pathology. Neuron 2004; 44: 601-607.

5 Nichols WC, Pankratz N, Hernandez D et al: Genetic screening for a single common LRRK2 mutation in familial Parkinson's disease. Lancet 2005; 365: 410-412.

6 Di Fonzo A, Rohe CF, Ferreira J et al: A frequent LRRK2 gene mutation associated with autosomal dominant Parkinson's disease. Lancet 2005; 365: 412-415.

7 Gilks WP, Abou-Sleiman PM, Gandhi S et al: A common LRRK2 mutation in idiopathic Parkinson's disease. Lancet 2005; 365: 415-416.

8 Kachergus J, Mata IF, Hulihan $M$ et al: Identification of a novel LRRK2 mutation linked to autosomal dominant parkinsonism: evidence of a common founder across European populations. Am J Hum Genet 2005; 76: 672-680.

9 Hernandez DG, Paisan-Ruiz C, McInerneyLeo A et al: Clinical and positron emission tomography of Parkinson's disease caused by LRRK2. Ann Neurol 2005; 57: 453-456.

10 Bonifati V, Oostra BA, Heutink P: Unraveling the pathogenesis of Parkinson's disease - the contribution of monogenic forms. Cell Mol Life Sci 2004; 61: 1729-1750.
11 Di Fonzo A, Tassorelli C, De Mari M et al: Comprehensive analysis of the LRRK2 gene in sixty families with Parkinson's disease. Eur J Hum Genet 2006; 14: 322-331.

12 Goldwurm S, Di Fonzo A, Simons EJ et al: The G6055A (G2019S) mutation in LRRK2 is frequent in both early and late onset Parkinson's disease and originates from a common ancestor. J Med Genet 2005; 42: e65.

13 Paisan-Ruiz C, Lang AE, Kawarai $\mathrm{T}$ et al: LRRK2 gene in Parkinson disease: mutation analysis and case-control association study. Neurology 2005; 65: 696-700.

14 West AB, Moore DJ, Biskup S et al: Parkinson's disease-associated mutations in leucine-rich repeat kinase 2 augment kinase activity. Proc Natl Acad Sci USA 2005; 102: $16842-16847$.

15 Lu CS, Simons EJ, Wu-Chou YH et al: The LRRK2 I2012T, G2019S, and I2020T mutations are rare in Taiwanese patients with sporadic Parkinson's disease. Parkinsonism Relat Disord 2005; 11: 521-522.

16 Infante J, Rodriguez E, Combarros O et al: LRRK2 G2019S is a common mutation in Spanish patients with late-onset Parkinson's disease. Neurosci Lett 2005; 395: 224-226.

17 Bras JM, Guerreiro RJ, Ribeiro MH et al: G2019S dardarin substitution is a common cause of Parkinson's disease in a Portuguese cohort. Mov Disord 2005; 20: 16531655.

18 Lesage S, Leutenegger A-L, Ibanez $\mathrm{P}$ et al: LRRK2 haplotype analyses in European and North African families with Parkinson's disease: a common founder for the G2019S mutation dating from the 13th century. $\mathrm{Am}$ J Hum Genet 2005; 77: 330-332.

19 Gloeckner CJ, Kinkl N, Schumacher A et al: The Parkinson disease causing LRRK2 mutation I2020T is associated with increased kinase activity. Hum Mol Genet 2006; 15: $223-232$. 